\title{
Evaluation of Synchronization and MPPT Algorithms in a DFIG Wind Turbine Controlled by an Indirect Matrix Converter
}

\author{
Ahmad Khajeh ${ }^{1}$, Reza Ghazi ${ }^{2}$, Mohamad Hosseini Abardeh ${ }^{3}$, Mahmoud Oukati Sadegh ${ }^{4}$ \\ ${ }^{1,4}$ University of Sistan and Baluchestan, Iran \\ ${ }^{2}$ Ferdowsi University of Mashhad, Iran \\ ${ }^{3}$ Islamic Azad University of Shahrood, Iran
}

\begin{tabular}{|c|c|}
\hline Article Info & ABSTRACT \\
\hline Article history: & Most of generators utilized in wind turbines are the Doubly-Fed Induction \\
\hline & Generator (DFIG). Indirect matrix converter (IMC) is a candidate for \\
\hline Recelved Dec 9, 201/ & substituting the traditional back-to-back converter in the future due to \\
\hline Revised Jan 12, 2018 & advantages gained by elimination of electrolytic capacitor. Starting DFIG \\
\hline Accepted Jan 26, 2018 & $\begin{array}{l}\text { wind turbines and synchronizing to the grid is a challenge in practice because } \\
\text { of large inrush currents that could damage switches. Synchronizing the DFIG }\end{array}$ \\
\hline Keyword: & $\begin{array}{l}\text { wind turbine controlled by the IMC is presented in this paper. Also, } \\
\text { maximum power point tracking algorithm performance of this configuration }\end{array}$ \\
\hline $\begin{array}{l}\text { DFIG } \\
\text { Indirect matrix converter } \\
\text { Wind turbine }\end{array}$ & $\begin{array}{l}\text { is examined. A laboratory scale prototype of the proposed configuration is } \\
\text { built. Experimental results have confirmed effectiveness of this } \\
\text { configuration. }\end{array}$ \\
\hline
\end{tabular}

Copyright (C) 2018 Institute of Advanced Engineering and Science. All rights reserved.

Corresponding Author:

Ahmad Khajeh,

University of Sistan and Baluchestan, Iran

Email: akhajeh@ece.usb.ac.ir

\section{INTRODUCTION}

One of the main resources of the renewable energy in the power systems is the wind power. Global Wind Energy Council report indicates that the cumulative installed capacity of the wind power throughout the world has reached to the $486 \mathrm{GW}$ up to end of 2016 year. Among the different types of generators, the DFIG due to its merits has the biggest share in the wind power market. The stator of the DFIG is connected directly to the grid while the rotor is controlled by an ac-ac power electronics converter. The DFIG wind turbine needs a power electronics converter sized about $30 \%$ of the nominal power to control active and reactive power separately. Traditionally, back-to-back converter is used to control the DFIG wind turbines. The IMC is an emerging ac-ac converter that could be used along with DFIGs in the future wind turbines. Some of the advantages of the IMCs compared to the back-to-back ones are as follow [1]: elimination of bulky electrolytic capacitor, lower size, higher efficiency and increased reliability. Therefore, in this paper indirect matrix converter is used as power electronics converter instead of commonly used back-to-back converter as shown in Figure 1.

A lot of works have been done studying performance of the DFIGs wind turbines during steady state and fault conditions [2]-[7]. Starting a DFIG wind turbine and connecting it to the grid is really a challenge from practical point of view due to big inrush currents that could be appeared if the DFIG is not synchronized with the power grid before the connection. These high currents could damage semiconductor switches of the power electronics converter. Therefore, before connecting the DFIG to the grid, the stator voltages must be synchronized to the grid. In real situations, a common method to measure the rotor angle and speed is using an incremental encoder connected to the shaft of the generator. Another issue related to this subject is 
encoder offset angle. This problem caused by the fact that the encoder zero angle is not aligned with the actual rotor windings angle. There are just a few papers in the literature that have considered this challenges[8]-[14].

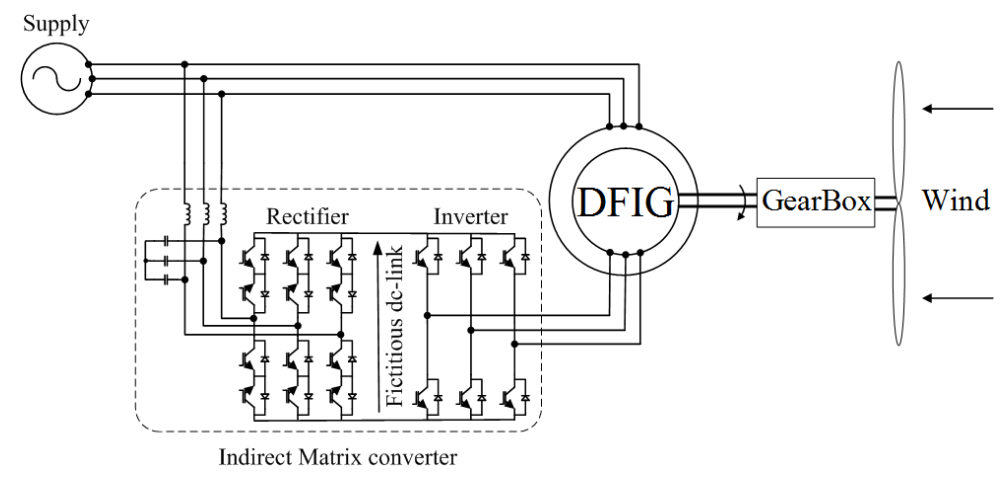

Figure 1. Wind Turbine based on the DFIG excited by IMC

One approach to obtain the offset value between encoder and actual rotor angle, is based on injecting balanced three-phase voltages into the rotor circuit before the synchronization process, and measuring the phase of the stator voltages and rotor currents [8]-[9]. According to the zero stator current, rotor and stator fluxes in this case are in line with the rotor current space vector. So by measuring the angle of the stator voltage and rotor current at a certain moment, the initial angle of the rotor is obtained. The reliability of this method is low in presence of measuring noise and disturbance in the system. Reference [10] has proposed to use the integral variable structure control for DFIG synchronization to the network.

Another method is based on the PLL and DFIG vector control [11]-[12]. In this method, estimation of the encoder offset angle and synchronizing the generator are done simultaneously. In this case, the rotor currents induce voltages in the stator of the generator. Due to the oscillations existing in the rotor currents, stator voltages contain harmonics. A low pass filter is used to remove these harmonics in the stator voltages. Most of researchers have used vector control method to decouple control of the active and reactive power of the DFIG, due to advantages same as fewer harmonics injected to the grid. Also, direct power control is utilized by some authors as a more convenient method for realization to control the DFIG. Therefore, synchronization of the DFIG to the gird using direct power control is investigated in [13]-[14].

Utilizing matrix converters in DFIG wind turbines is still in research phase. Most of the recent works have dealt with their normal operation [15]-[21]. Direct torque control and fuzzy logic control of the DFIG with an IMC are presented in [18]-[19]. In [20] the model predictive control of a DFIG with an IMC is reported. Dynamic performance of a DFIG using IMC under the voltage dip conditions has been discussed in [21]. In Ref [22] an indirect matrix converter is used to drive a fixed speed wind turbine system. Simulation results presented in [22] show that the system harmonics content of the voltages and currents are reduced by using IMC. Therefore, the IMC is a good candidate substituting back-to-back converter in wind turbines application.

Published works in the subject of DFIG synchronization have devoted to the back-to-back power converter configuration. As far we know, there is no published work related to vector control of DFIG with IMC synchronization problem in the literature. Therefore, the main goal of this paper is synchronizing the DFIG with IMC to the grid for safe connection and injecting MPPT power to the grid. Furthermore, using IMC to control DFIG wind turbines is in research phase and most of published works are based on simulation results. In this paper, a laboratory scale prototype is constructed to demonstrate effectiveness of the proposed system practically. Also, Implementation of the experimental setup with the low-cost ARM-based microcontroller is described with details in a section that could be a good reference for those interesting to practical aspects of the power electronics converters.

This paper is organized as follows. In section 2, modeling and control of the DFIG based wind turbine is presented. The encoder calibration and synchronization of the DFIG is discussed in section 3. Experimental results from a laboratory prototype are presented in section 4 . Finally, section 5 concludes the paper. 


\section{MODELING AND CONTROL OF THE SYSTEM}

In this section, dynamic model of a DFIG based wind turbine is provided. The stator winding of the DFIG is directly connected to the grid, and the rotor winding is coupled via an IMC. The IMC must handle the slip power, i.e. about $30 \%$ of the rated power of the wind turbine. The speed range of the generator is typically $\pm 30 \%$ of synchronous speed, thus providing a flexibility of operation in both sub and super synchronous modes, depending on the wind conditions.

\subsection{Turbine Model}

The mechanical power extracted by a wind turbine from the wind is expressed by

$$
P=\frac{1}{2} A \cdot \rho \cdot C_{p}(\lambda, \beta) \cdot v_{w}^{3}
$$

Where $\mathrm{A}$ is the area covered by the rotor blades, $\rho$ is the air density, $\mathrm{Cp}$ is the power coefficient, representing the amount of power that a turbine can extract, and $\mathrm{vw}$ is the wind speed. The power available in the wind cannot be extracted completely. Theoretically the maximum captured power is $59 \%$ of the power available in the wind. The power coefficient is a function of the tip-speed ratio $\lambda$ and the pitch angle of the rotor blades $\beta$. The tip-speed ratio is defined by

$$
\lambda=\frac{R \Omega_{t}}{v_{w}}
$$

Where $\mathrm{R}$ is the radius of the rotor blades and $\Omega \mathrm{t}$ is the angular speed of the blades. For each pitch angle of the rotor blades, there is an optimum tip-speed ratio $\lambda$ opt for which $\mathrm{Cp}(\lambda \mathrm{opt}, \beta)$ takes a maximum value. Therefore, for wind speeds below rated value, the existing power is below the rated power, so power coefficient is optimized by adjusting the tip-speed ratio to achieve the maximum power coefficient. The pitch angle is kept constant in this region and this process is called the maximum power point tracking (MPPT) of wind turbines. On contrary, at wind speeds above the rated value the extracted wind power has to be limited by means of blade pitching. In this paper the MPPT is accomplished through a look-up table[23].

\subsection{DFIG model}

A fifth-order dynamic model of the DFIG is used in this paper. The electrical model of the DFIG in the two-axis d-q synchronous reference frame is given by [24]

$$
\begin{aligned}
& v_{d s}=R_{s} i_{d s}+\frac{d \psi_{d s}}{d t}-\omega_{s} \psi_{q s} \quad \psi_{d s}=L_{s} i_{d s}+L_{m} i_{d r} \\
& v_{q s}=R_{s} i_{q s}+\frac{d \psi_{q s}}{d t}+\omega_{s} \psi_{d s} \quad \psi_{q s}=L_{s} i_{q s}+L_{m} i_{q r} \\
& v_{d r}=R_{r} i_{d r}+\frac{d \psi_{d r}}{d t}-\left(\omega_{s}-\omega_{r}\right) \psi_{q r} \quad ; \quad \psi_{d r}=L_{m} i_{d s}+L_{r} i_{d r} \\
& v_{q r}=R_{r} i_{q r}+\frac{d \psi_{q r}}{d t}+\left(\omega_{s}-\omega_{r}\right) \psi_{d r} \quad \psi_{q r}=L_{m} i_{q s}+L_{r} i_{q r} \\
& T_{e m}=\frac{p}{2}\left(\psi_{q r} i_{d r}-\psi_{d r} i_{q r}\right) \quad L_{s}=L_{l s}+L_{m} \quad, \quad L_{r}=L_{l r}+L_{m}
\end{aligned}
$$

In these equations, $\mathrm{Rs}, \mathrm{Rr}, \mathrm{Ls}, \mathrm{Lr}, \mathrm{Lls}$, and Llrare the resistances and inductances of the stator and rotor windings, Lm is the magnetizing inductance, vds, vqs, vdr, vqr, ids, iqs, idr, iqr, $\psi d \mathrm{ds}, \psi q \mathrm{q}, \psi \mathrm{dr}$, and $\psi \mathrm{qr}$, are $\mathrm{d}$ and q components of the space vectors of the stator and rotor voltages, currents, and fluxes respectively, $\omega \mathrm{s}$ is the synchronous speed of generator, $\omega \mathrm{r}$ is the electrical speed of rotor, and $\mathrm{p}$ is the number of poles. 


\subsection{Indirect Matrix Converter}

The main advantages of a matrix converter are: robustness, reliability with less size and weight due to the absence of the bulky electrolytic capacitor, controllable input power factor, nearly sinusoidal input current and output voltage with only switching frequency harmonics, along with bidirectional power flow[25]. The direct matrix converter (DMC) encounters the commutation problems requiring a complex control circuitry. While in IMC all switches at the line side will turn on and off at zero current, so the commutation problems are eliminated [26]-[27]. Therefore, the IMC is an interesting converter for wind energy applications regarding its robustness, reduced size and reliability concerns.

Due to the advantages of the IMC over the back-to-back converters, in this paper the IMC is used to control the DFIG. An IMC consists of a rectification part on the input side and an inversion part on the output side, connected via fictitious dc-link as shown in Figure 1. The rectifier has six bidirectional switches with the ability of conducting current and blocking voltage in both directions. The rectifier side objective is to achieve maximum positive voltages at the fictitious dc-link and sinusoidal input currents. Usually the grid side converter of the DFIG is controlled to exchange zero reactive power at the grid point.

The inverter of the IMC is used to control the active and reactive power of the DFIG. Depending on the rotor speed, the IMC will either absorb power (sub-synchronous) from grid or inject power (supersynchronous) to the grid. Therefore, the IMC must have the ability of bidirectional power flow to the network. On the output stage, the space vector modulation (SVM) is used to generate the required rotor voltage space vector by currents controllers. Detail description of the IMC modulation technique is provided in [16].

\subsection{Vector Control of the DFIG}

The goal of the DFIG controller is the independent control of the stator active and reactive power. The active power reference is determined by MPPT algorithm and the reactive power is set in order to achieve the desired power factor. Stator flux d-q reference frame is the most widely used DFIG vector control in the wind turbine applications. In DFIG, the rotor voltages are control variables which control the rotor currents.

The stator active and reactive power can be calculated as [6]

$$
\begin{aligned}
& P_{s}=-\frac{3}{2} V_{s} \frac{L_{m}}{L_{s}} i_{q r} \\
& Q_{s}=\frac{3 V_{s}}{2 L_{S}}\left(\psi_{s}-L_{m} i_{d r}\right)
\end{aligned}
$$

The above equations clearly show that under the stator flux orientation, the active and reactive powers are decoupled and can be controlled via the rotor currents. By means of iqr, we can control the active power while the reactive power can be controlled via idr. Using the above equations, the reference currents can be calculated from the desired powers.

\section{SYNCHRONIZATION PROBLEM}

Starting a wind turbine based on the DFIG require to a complicated algorithm. When the wind speed reaches to the minimum required speed, connecting procedure of the wind turbine will be started. At first, the turbine speed is controlled by the pith angle control mechanism. After reaching the speed to the operation area of the DFIG, the synchronization procedure must be done. Schematic of the DFIG wind turbine with the IMC showing required switches for synchronization is depicted in Figure 2. To synchronize the DFIG with the grid, SW1 and SW2 switches are connected sequentially. Therefore, power electronics converter is energized and could be used to control the stator voltages of the DFIG for being synchronous to the grid voltages. Furthermore, due to physical three-phase winding on the rotor, it is needed to calibrate the zeroposition of the encoder angle with the actual angle of the rotor winding. Synchronizing the DFIG and calibration of the encoder are based on the same circuitry, in point of the system configuration. In both cases, SW3 switch is open and the stator current is zero. Therefore, only after synchronization procedure the SW3 and DFIG could be safely connected to the grid. In the following, DFIG synchronization and encoder calibration problems are described:

\subsection{Encoder Calibration}

Converting quantities between different reference frames in the vector control of the DFIG require to the rotor angle position. The rotor angle could be obtained by an incremental encoder or through sensorless 
methods. In case of using encoder, generally the encoder angle is not aligned with the actual rotor angle. This problem occurs due to the fact that the space vector of the rotor linkage flux is concluded from the actual distribution of the rotor windings. Therefore, alignment of the encoder angle with actual rotor angle is accidentally and there is a constant offset between them due to zero position mismatches of them. Consequently, to implement vector control of the DFIG correctly, it is required to modify the encoder angle by an offset. Space vector diagrams of the stator and rotor describing this problem are depicted in Figure 3. It is clear from Figure 3 that the offset angle ( Ooff), must be estimated to implement the vector control correctly.

\subsection{Encoder offset estimation and DFIG synchronization}

Encoder offset estimation and DFIG synchronization used in this work is based on the PLL and DFIG vector control [11]-[12]. In this method, estimation of the encoder offset angle and synchronizing the generator are done simultaneously. In this case, the rotor currents induce voltages in the stator of the generator. Synchronous reference frame angle can be achieved using a PLL. Therefore, three-phase voltages are transformed to the synchronous reference frame by the output angle of the PLL. In the synchronous reference frame aligned with the stator flux vector control, d-component of the grid voltage space vector is zero and the q-component is equal to the maximum of the grid voltage. Also, the stator voltages convert to the synchronous reference frame with the same angle i.e. the PLL output angle figure. Therefore, under the same transformation angle, the stator voltages are synchronous to the grid voltages provided that the dcomponent of the stator voltage space vector is zero. Consequently, a synchronization method could be designed based on this fact. In this method, the error of the d-component of the voltage space vector is fed to a PI controller, and the controller output is equal to the offset angle as follows:

$$
\begin{aligned}
& V_{d-e r r}=V_{d g}-V_{d s} \\
& \theta_{\text {off }}=\left(k_{p}+\frac{k_{i}}{s}\right) V_{d-e r r}
\end{aligned}
$$

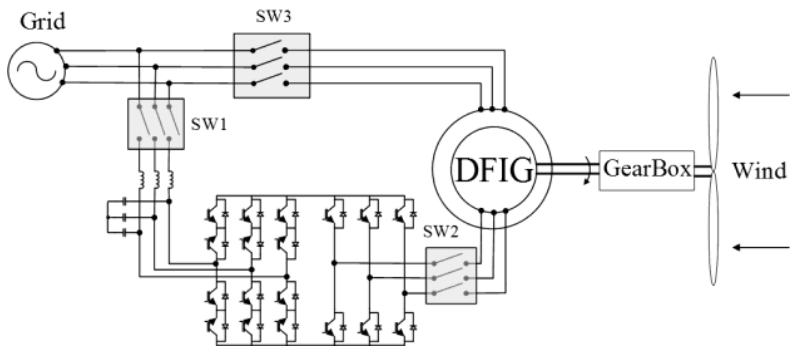

Figure 2. Configuration of the system along with starting switches
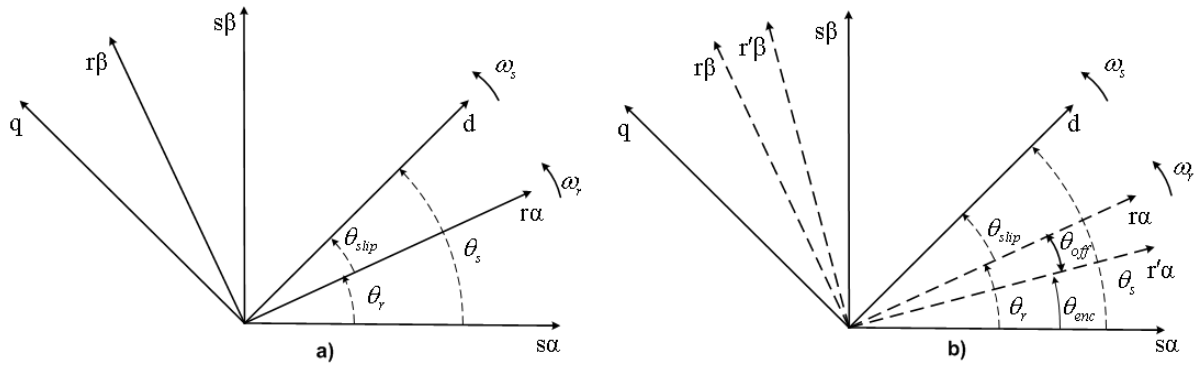

Figure 3. space vector diagrams of the stator and rotor frames to describe the encoder offset problem

To complete the synchronization process, it is mandatory to design a method for amplitude adjustment of the stator induced voltage with the grid. According to the same angle used in the synchronous 
reference frame transformation, equality of the q-component of voltages on both sides of the SW3 means that the stator voltage amplitude is equal to the grid. From equations 3 and zero stator currents in this stage, it is deduced that the induced stator voltages are proportional to the d-component of the rotor current. Consequently, the amplitude of the stator voltage space vector could be controlled by a PI controller with the q-component error of the space vectors as input and the d-component of the rotor current as output. To increase the speed, the required d-component of the rotor current for the steady state voltage in the stator voltage is added to the control system as a feed-forward term. Therefore, the final controller of the stator voltage amplitude is as follow:

$$
\begin{aligned}
& V_{q-e r r}=V_{q g}-V_{q s} \\
& i_{d r}^{*}=\left(k_{p}+\frac{k_{i}}{s}\right) V_{q-e r r}+\frac{V}{\omega_{s} L_{m}}
\end{aligned}
$$

Finally, due to the lack of reactive power exchange in this case, the reference value of q-component of the rotor current is made equal to zero. Therefore, a DFIG synchronization method in terms of the amplitude and phase to the grid with encoder offset modification and high reliability could be achieved. Block diagram of the overall control system of DFIG synchronization with the grid is depicted in Figure 4.

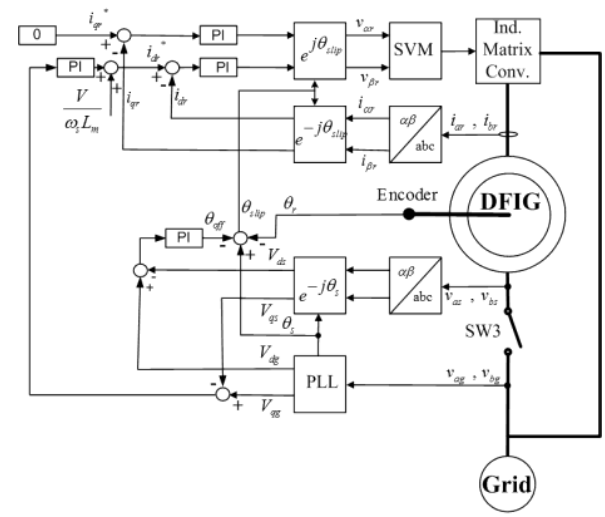

Figure 4. Overall block diagram of the synchronization algorithm of the DFIG to the grid

\subsection{PLL}

Synchronization is one of the most important parts of the power electronics converters connected to the network. The phase angle of the positive sequence of the grid voltage must be measured in real time in order to precisely control the converter. In the majority of new control algorithms, phase angle and frequency of the grid voltage is measured through phase-locked loop (PLL). With the development of power electronics converters and high importance of accurate connection to the grid, the digital PLL structure is designed for measuring the phase angle and frequency of the grid voltage. The synchronous reference frame PLL is the most structure used in the converters connected to the grid [28]-[30].

The block diagram of linearized synchronous reference frame PLL is shown in Figure 5.

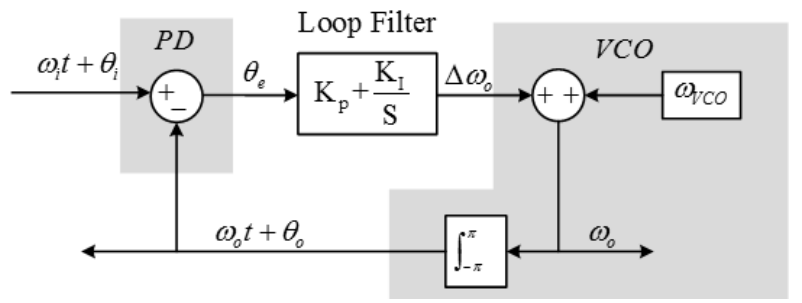

Figure 5. Linearized synchronous reference frame PLL block diagram 


\section{RESULTS AND DISCUSSION} as described further.

In order to verify the operation of the proposed method, a laboratory-scale prototype is developed,

\subsection{Experimental Hardware Setup}

An illustration of the laboratory prototype is shown in Figure 6, composed of two parts: power part and the converter and control part. In the input stage of the power section, there is a main contactor that connects the system to the three-phase utility. A variable three-phase power supply is connected to the main switch. A laboratory $1.5 \mathrm{~kW}$ DFIG is used as the generator of the wind turbine. The parameters of the DFIG and the type of experimental components are listed in the appendix. Due to the different poles (DFIG: 4 poles and Induction Motor: 2 poles)the shaft of the DFIG is connected to a cage induction motor through a pulley and belt system. To emulate the wind speed, the speed of the induction motor is controlled by a commercial drive (VFD-M 2.2kW from Delta Electronics, Inc.). An incremental 3600 PPR optical encoder from Autonics Company, is added to the shaft of the DFIG to obtain the speed and position of the generator for the control system. The synchronization algorithm needs stator voltages, therefore two voltage sensor is connected to the stator of the DFIG.

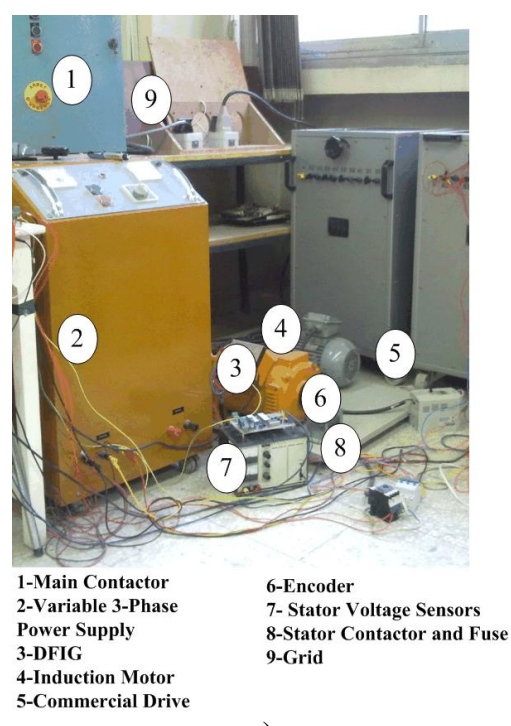

a)

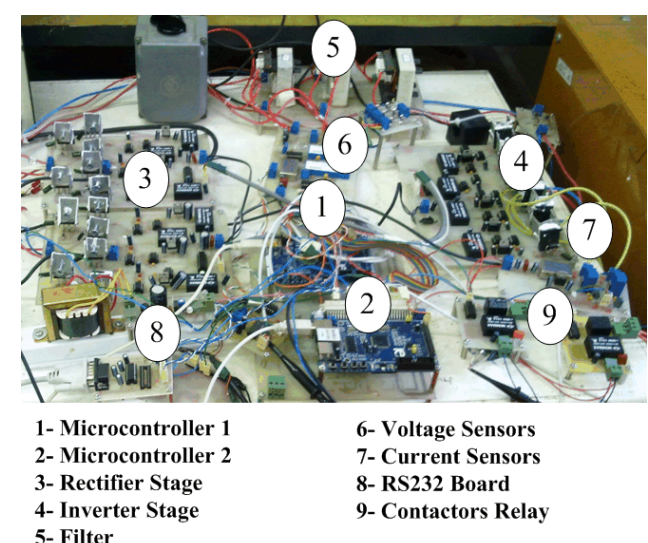

5- Filter

Figure 6. Laboratory prototype test rig: a) Power Section and b) Converter and Control Section

In the converter and control section of the test rig, two microcontrollers are used for the simplicity of the implementation. One microcontroller is dedicated to the SVM modulation of the indirect matrix converter and generation of the gates signals. The second microcontroller is responsible for control implementation. The rectifier and inverter parts of the indirect matrix converter are made by 18 IGBT switches (1MBH30D) from Fuji Electric Company. The switching frequency of the converter is set to $2 \mathrm{kHz}$. To suppress the currents harmonics, a RLC filter $(\mathrm{R}=10 \Omega, \mathrm{L}=1 \mathrm{mH}, \mathrm{C}=20 \mu \mathrm{F})$ is used at the point of converter connection to the supply. AD202J from ANALOG DEVICES is utilized as voltage sensor. Currents sensors are LTS 25-NP from LEM Company. In order to verify the vector control of the DFIG, we need to compare d-q components of the rotor currents to their references. Furthermore, these parameters could not be measured physically and they exist in the microcontroller. Therefore, a serial communication board is fabricated to transfer these components from microcontroller to the MATLAB. Also, Relays are used to convert the microcontroller signals to the power signals of the contactors.

\subsection{Experimental Results}

According to the balanced three-phase input voltages, just two sensors are used to measure two lineto-line voltages. Sensed voltages in the input pins of the microcontroller's ADC contain dc component. To remove the DC value of sensed voltages, a high-pass filter is used. Then, using the two measured voltages, natural three-phase to the stationary two-phase reference frame conversion have been made. Transformation 
from the stationary to the synchronous reference frame is done by the PLL output angle. For this purpose, a digital synchronous reference frame PLL is designed and implemented in the microcontroller. The input lineto-line voltage and the q-axis component in the synchronous reference frame are presented in Figure 7.a. The q-axis component of the voltage space vector is nearly zero that means the correct performance of the implemented PLL. Furthermore, the input line-to-line voltage and the output voltage of the PLL are depicted in Figure 7.b. As it is clear from Figure 7.b, PLL output angle is locked to the input voltage angle.

To safely connect the DFIG to the grid, the synchronization method as mentioned earlier, is implemented in the microcontroller. The grid and induced stator voltages before filtration, using described synchronization method are presented in. As it is shown, after $60 \mathrm{~ms}$ the stator voltage is synchronous with the grid in terms of amplitude and the phase angle. Consequently, the DFIG is synchronized to the grid and connection of the generator to the grid is safe. It is evident from the that the induced voltages in the stator of the DFIG contain harmonics. This occurs due to oscillations exist in the rotor current and the stator voltages are induced by the rotor currents before connection to the grid.

To test the vector control and current controllers' performance of the system, a step change is applied to the d-axis component reference of the rotor current. The value of the d-axis component reference has changed from 1 to 2 and after 1.2s to 0.5Error! Reference source not found.. As it is clear from the figure, the vector control works very well and the real value track the reference with acceptable accuracy. Furthermore, the speed of the induction motor has been changed to emulate the real wind characteristic. As discussed earlier, the q-axis component of the rotor current is proportional to the active power injected to the utility. Through the MPPT algorithm, the active power reference is achieved from a look-up table that the input is the speed of the DFIG. The q-axis component of the rotor current for the MPPT test is depicted in the

. Comparison of the real and reference values in this figure shows that the MPPT algorithm works well in the prototype to inject maximum power to the utility.

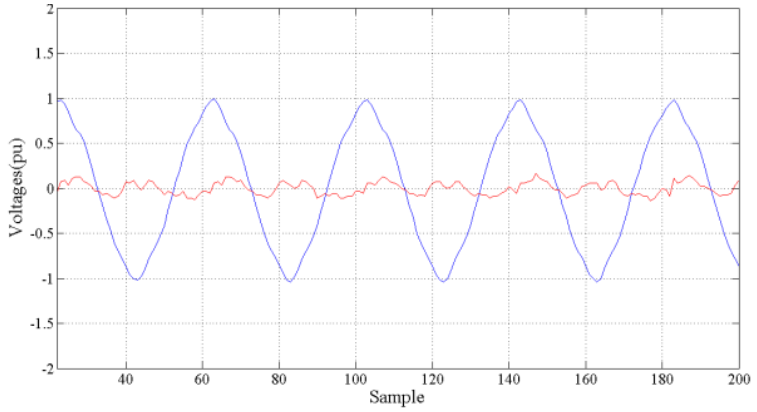

a)

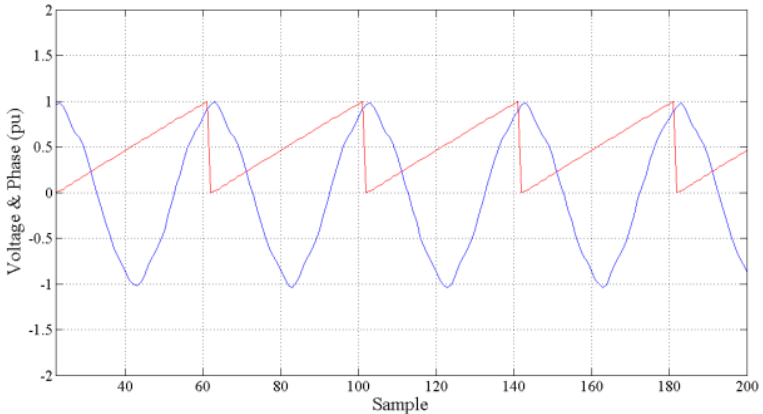

b)

Figure 7. Experimental results of synchronous reference frame PLL implemented in the microcontroller: a) instantaneous line-to-line voltage of the grid and the error signal of the $\mathrm{Vq}$ (in pu), and b) instantaneous lineto-line voltage of the grid and output angle of the PLL

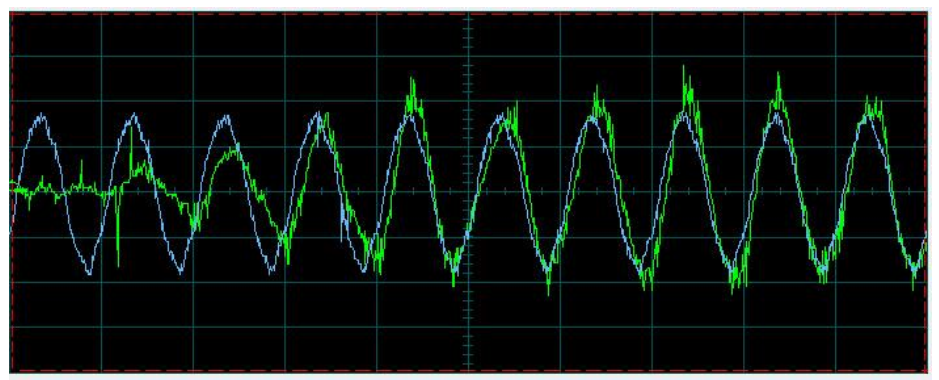

Figure 8. Experimental results of synchronization algorithm: the grid voltage (blue curve) and the induced voltage in the stator of the DFIG before filtration (green curve) 


\section{DC CONCLUSION}

From practical point of view, starting and synchronizing a DFIG wind turbine is really a challenge due to possible inrush currents. There are just few works in the literature studied DFIG safe synchronization to the grid with the back-to-back converter. In this paper, an efficient synchronization method is used to connect DFIG wind turbine excited by an indirect matrix converter as a candidate to replace the conventional back-to-back converter due to its merits such as elimination of the bulky electrolytic capacitor. Experimental results of a laboratory scale prototype confirmed effectiveness of the described method. In addition, MPPT algorithm is implemented in the microcontroller to test MPPT performance of the DFIG wind turbine with the IMC, and MPPT performance is verified by the experimental results.

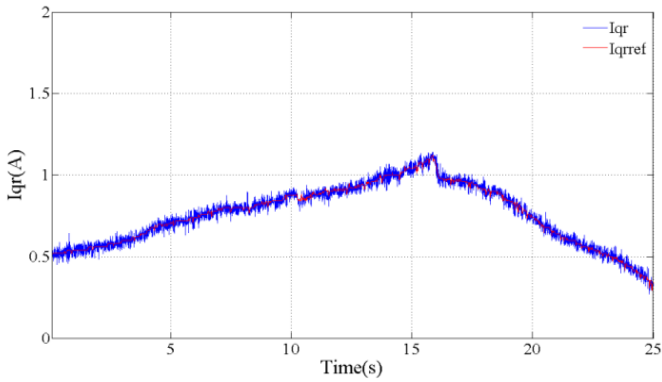

Figure 9. Realization of MPPT algorithm to inject maximum power from the wind to the grid: the q-axis component of the rotor current, reference (red line) and measured (blue line)

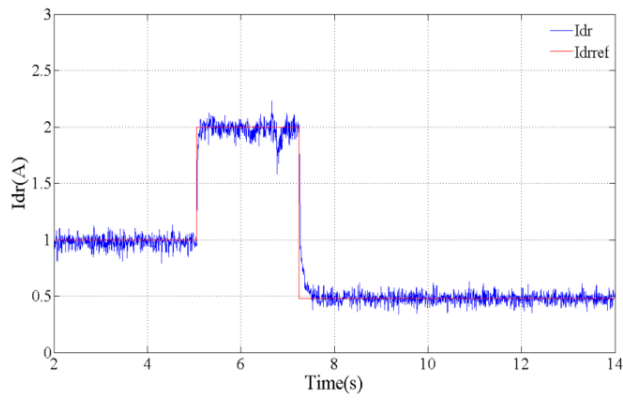

Figure 10. Vector control of the DFIG performance result: a step change in the reference value of the $\mathrm{d}$ axis component of the rotor current, reference (red line) and measured (blue line)

\section{REFERENCES}

[1] Gang Li, "Realization of SVM Algorithm for Indirect Matrix Converter and Its Application in Power Factor Control," Advances in Power Electronics, vol. 2015, Article ID 740470, 10 pages, 2015. doi:10.1155/2015/740470

[2] Rahimi M, Parniani M. Efficient control scheme of wind turbines with doubly fed induction generators for lowvoltage ride-through capability enhancement.IET Renewable Power Generation2010; vol.4, no.3, 242-252.

[3] Kiarash A, Murtaza F, Mohammad F, K. Efficient Approach to LVRT Capability of DFIG-Based Wind Turbines under Symmetrical and Asymmetrical Voltage Dips Using Dynamic Voltage Restorer. International Journal of Power Electronics and Drive Systems (IJPEDS) Vol 8 No 5, 2017 pages 945-956

[4] Hua G, Cong L, Geng Y. LVRT Capability of DFIG-Based WECS Under Asymmetrical Grid Fault Condition. IEEE Transactions on Industrial Electronics2013; vol.60, no.6, 2495-2509.

[5] Venu Madhav G, Obulesu Y. P., A Fuzzy Logic Control Strategy for Doubly Fed Induction Generator for Improved Performance under Faulty Operating Conditions. International Journal of Power Electronics and Drive Systems (IJPEDS) Vol 4 No 4, 2014 pages 419-429

[6] Khajeh A, Ghazi R. GA-Based Optimal LQR Controller to Improve LVRT Capability of DFIG Wind Turbines. Iranian Journal of Electrical and Electronic Engineering. 2013;9(3):167-76.

[7] Myat Thin A, Yuzana Kyaing N. S., Performance Analysis of Doubly Fed Induction Generator Using Vector Control Technique. International Journal of Power Electronics and Drive Systems (IJPEDS) Vol 5 No 5, 2015

[8] Tapia, G.; Santamaria, G.; Telleria, M.; Susperregui, A., "Methodology for Smooth Connection of Doubly Fed Induction Generators to the Grid," Energy Conversion, IEEE Transactions on, vol.24, no.4, pp.959,971, Dec. 2009

[9] Cortajarena, J. A.; De Marcos, J.; Alvarez, P.; Vicandi, F. J.; Alkorta, P., "Start up and control of a DFIG wind turbine test rig," IECON 2011 - 37th Annual Conference on IEEE Industrial Electronics Society , vol., no., pp.2030,2035, 7-10 Nov. 2011

[10] Si Zhe Chen; Cheung, N.C.; Ka Chung Wong; Jie Wu, "Grid Synchronization of Doubly-fed Induction Generator Using Integral Variable Structure Control," Energy Conversion, IEEE Transactions on , vol.24, no.4, pp.875,883, Dec. 2009

[11] Sadara, W.; Neammanee, B., "Implementation of a three phase grid synchronization for doubly-fed induction generators in wind energy system," Electrical Engineering/Electronics Computer Telecommunications and Information Technology (ECTI-CON), 2010 International Conference on , vol., no., pp.1016,1020, 19-21 May 2010

[12] Jungwoo Park; Kiwook Lee; Dongwook Kim; Kwangsoo Lee; Jinsoon Park, "An encoder-free grid synchronization method for a Doubly-fed Induction Generator," Power Electronics and Applications, 2007 European Conference on , vol., no., pp.1,6, 2-5 Sept. 2007

[13] M. Shahroozi, R. Ghobadi and A. Radan, "Using virtual direct power control for synchronizing DFIG with grid," Power Electronics, Drive Systems and Technologies Conference (PEDSTC), 2014 5th, Tehran, 2014, pp. 96101. 
[14] S. Mahmodicherati, M. Elbuluk and Y. Sozer, "Grid synchronization for a virtual direct power-controlled DFIG wind power system," 2015 IEEE Energy Conversion Congress and Exposition (ECCE), Montreal, QC, 2015, pp. 1013-1020.

[15] Amini J, Kazemzahed R, Madadi Kojabadi H. Performance enhancement of indirect matrix converter based variable speed Doubly-Fed induction generator.1st Power Electronic \& Drive Systems \& Technologies Conference (PEDSTC)2010; 450-455.

[16] Reyes E, Pena R, Cardenas R, Clare J, Wheeler P. Control of a Doubly-fed Induction Generator with an Indirect Matrix Converter with changing

[17] DC voltage. IEEE International Symposium on Industrial Electronics (ISIE) 2010; 1230-1235.

[18] Yarahmadi, A, KhaburiDA, BehniaH.Direct Virtual Torque Control of DFIG grid connection using Indirect Matrix Converter. 3rd Power Electronics and Drive Systems Technology (PEDSTC) 2012; 115-120.

[19] CalvilloCF, MartellF, ElizondoJL, Avila A, MaciasME, RiveraM, RodriguezJ. Rotor current fuzzy control of a DFIG with an Indirect Matrix Converter. 37th Annual Conference on IEEE Industrial Electronics Society IECON2011; 4296-4301.

[20] Rivera, M, ElizondoJL, MaciasME, ProbstOM, MicheloudOM, RodriguezJ, RojasC, WilsonA.Model predictive control of a Doubly Fed Induction Generator with an Indirect Matrix Converter. 36th Annual Conference on IEEE Industrial Electronics Society IECON2010; 2959-2965.

[21] Wenlang D, Zhiyong C, Liming Z, Yu Y. Research on the performance of low voltage ride-through for doubly fed induction generator excited by two-stage matrix converter.IEEE 6th International Power Electronics and Motion Control Conference IPEMC 2009; 638-643.

[22] F. M. Savio, V. R. Rajan, B. Arun Kumaran and C. S. A. Sekhar, "Performance analysis of an improved low harmonic indirect matrix converter for drive system in WECS," Emerging Trends In New \& Renewable Energy Sources And Energy Management (NCET NRES EM), 2014 IEEE National Conference On, Chennai, 2014, pp. 214220.

[23] Michalke G. Variable speed wind turbines- modeling, control, and impact on power systems. PhD Thesis, Riso National Laboratory 2008.

[24] Zerzouri N, Labar H. Active and Reactive Power Control of a Doubly Fed Induction Generator. International Journal of Power Electronics and Drive Systems (IJPEDS) Vol 5 No 2, 2014 pages 244-251

[25] Kuldeep B, Subrat B. A Novel Control Strategy of Indirect Matrix Converter Using Space Vector Modulation. International Journal of Power Electronics and Drive Systems (IJPEDS) Vol 7 No 3, 2016 pages 926-935

[26] Wei L, Lipo TA. A novel matrix converter topology with simple commutation. 36th IEEE Industry Applications Conference IAS 2001.

[27] Nannapaneni L, Gopala Rao V., Control of Indirect Matrix Converter by Using Improved SVM Method. International Journal of Power Electronics and Drive Systems (IJPEDS) Vol 6 No 2, 2015 pages 370-375

[28] Golestan, S.; Monfared, M.; Freijedo, F.D., "Design-Oriented Study of Advanced Synchronous Reference Frame Phase-Locked Loops," Power Electronics, IEEE Transactions on, vol.28, no.2, pp.765,778, Feb. 2013

[29] Gonzalez-Espin, F.; Figueres, E.; Garcera, G., "An Adaptive Synchronous-Reference-Frame Phase-Locked Loop for Power Quality Improvement in a Polluted Utility Grid," Industrial Electronics, IEEE Transactions on , vol.59, no.6, pp.2718,2731, June 2012

[30] Freijedo, F.D.; Yepes, A.G.; López, O.; Vidal, A.; Doval-Gandoy, J., "Three-Phase PLLs With Fast Postfault Retracking and Steady-State Rejection of Voltage Unbalance and Harmonics by Means of Lead Compensation," Power Electronics, IEEE Transactions on, vol.26, no.1, pp.85,97, Jan. 2011

[31] Freijedo, F.D.; Doval-Gandoy, J.; Lopez, O.; Acha, E., "Tuning of Phase-Locked Loops for Power Converters Under Distorted Utility Conditions," Industry Applications, IEEE Transactions on , vol.45, no.6, pp.2039,2047, Nov.-dec. 2009

\section{APPENDIX: PARAMETERS OF THE STUDIED SYSTEM ARE AS FOLLOWS}

DFIG parameters:

$$
\begin{aligned}
& \mathrm{L}_{\mathrm{m}}=234 \mathrm{mH} \\
& \mathrm{L}_{\mathrm{ls}}=\mathrm{L}_{\mathrm{lr}}=14.5 \mathrm{mH} \\
& \mathrm{R}_{\mathrm{s}}=\mathrm{R}_{\mathrm{r}=2 \Omega} \\
& \mathrm{V}_{\text {nom }}=380 \mathrm{~V} \\
& \mathrm{P}_{\text {nom }}=1.5 \mathrm{~kW} \\
& \text { Turn Ratio }=1.055
\end{aligned}
$$

IGBT Type : 1MBH30D

Current Sensor : LTS 25-NP

Voltage Sensor : AD202

Microcontroller : SAM7X256 


\section{BIOGRAPHIES OF AUTHORS}

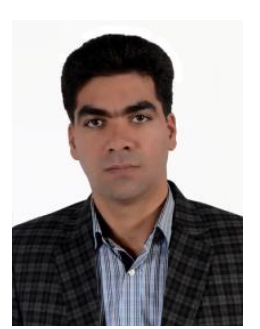

Ahmad Khajeh was born in Zabol, Iran in 1982. He received the B.Eng. degree from Sistan and Baluchestan Universtity, Zahedan, Iran, in 2004, and the M.Eng. and Ph.D. degrees from Amirkabir University of Technology and Ferdowsi University of Mashhad, Iran, in 2007 and 2014, all in electrical engineering, respectively. Currently, he is an Assistant Professor with the Faculty of Electrical and Computer Engineering, University of Sistan and Baluchestan, Zahedan, Iran. His current research interests include power electronics, wind power, adjustable speed drives and photovoltaic system.

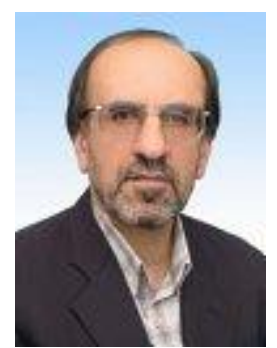

Reza Ghazi (M'90) was born in Semnan, Iran in 1952. He received his B.Sc., degree (with honors) from Tehran University of Science and Technology, Tehran, Iran in 1976. In 1986 he received his M.Sc degree from Manchester University, Institute of Science and Technology (UMIST) and the Ph.D. degree in 1989 from University of Salford UK, all in electrical engineering. Following receipt of the Ph.D degree, he joined the faculty of engineering Ferdowsi University of Mashhad, Iran as an Assistant Professor of electrical engineering. He is now Professor of Electrical Engineering in Ferdowsi University of Mashhad, Iran. His main research interests are reactive power control, FACTS devices, application of power electronic in power systems, distributed generation, restructured power systems control and analysis. He has published over 100 papers in these fields including three books.

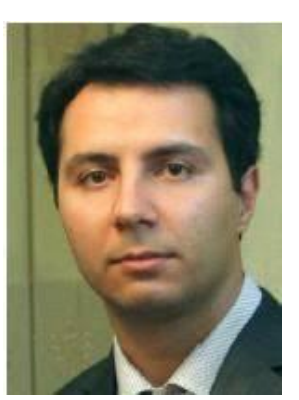

Mohamad Hosseini Abardeh received the B.Eng. degree from Ferdowsi University of Mashhad, Mashhad, Iran, in 2005, and the M.Eng. and Ph.D. degrees from University of Tarbiat Modares and Ferdowsi University of Mashhad, Iran, in 2008 and 2014, all in electrical engineering, respectively. Currently, he is an Assistant Professor with the Faculty of Engineering, Islamic Azad University of Shahrood, Shahrood, Iran. His current research interests include power electronics, wind power, adjustable speed drives and photovoltaic system.

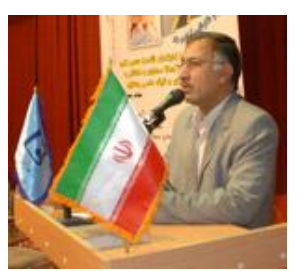

Mahmoud OUKATI SADEGH was born in 1966 in Zabol, Iran. He received the B.Sc. and M.Sc. degree in electrical power system engineering from Tehran University, Tehran, Iran, in 1989 and 1992 respectively. the Ph.D. degree in electrical engineering from Strathclyde University in Glasgow, UK in 2003. Currently, he is an Assistant Professor in the Department of Electrical and Electronic Engineering, University of Sistan and Baluchestan, Zahedan, Iran. His research interests are power system control and operation, Electrical distribution system and Smart grid. 